\title{
AS TEORIAS SEXUAIS INFANTIS NA ATUALIDADE: ALGUMAS REFLEXÕES
}

\author{
Silvia Maria Abu-Jamra Zornig
}

\begin{abstract}
RESUMO. O trabalho tem por objetivo retomar a concepção freudiana da sexualidade infantil, discutindo seu valor estruturante na constituição da subjetividade da criança. Ao demonstrar como Freud enfatiza a noção de uma construção subjetiva que é fundada a partir da relação com o outro, o texto subverte a noção de cronologia presente nas etapas do desenvolvimento psicossexual para ressaltar o fator infantil presente e inerente à condição humana.
\end{abstract}

Palavras-chave: sexualidade infantil, psicanálise, pulsão.

\section{CONSIDERATIONS ON CHILDREN'S CURRENT SEXUAL THEORIES}

\begin{abstract}
Current analysis discusses Freud's concept of infantile sexuality and its importance in the constitution of the child's subjectivity. Freud emphasizes the subject's constitution based on the relationship between the child and its primary caretakers and at the same time maintains the important notion of an infantile sexuality that is repressed but never suppressed from one's unconscious. Results show that the infantile factor is forever present both in children and in adults.
\end{abstract}

Key words: Infantile sexuality, Psychoanalysis, drive.

\section{LAS TEORÍAS SEXUALES INFANTILES EN LA ACTUALIDAD: ALGUNAS REFLEXIONES}

\begin{abstract}
RESUMEN. Este artículo tiene por objetivo retomar la concepción de Freud de la sexualidad infantil, discutiendo su valor estructurante en la constitución de la subjetividad del niño. Al demostrar como Freud enfatiza la noción de una construcción subjetiva a partir de la relación con el otro, el texto subvierte la concepción de cronología presente en las etapas del desarrollo psicosexual, para realzar el factor infantil presente e inherente a la condición humana.

Palabras-clave: sexualidad infantil, psicoanálisis, pulsión.
\end{abstract}

A sexualidade das crianças é um tema difícil de ser abordado, pois apesar de Freud ter chocado a sociedade vienense cem anos atrás, ao propor a idéia de uma infância que se afastava da tradicional noção de pureza e de felicidade ímpar, trazendo à tona uma criança dotada de afetos, desejo e conflitos, ainda hoje temos dificuldade em aceitar a sexualidade infantil proposta pelo fundador da psicanálise.

Em nossa cultura denominada pós-moderna, as crianças se vestem como adultos, têm agenda de executivos e são impelidas a adotar um modelo sexual que muitas vezes ultrapassa sua compreensão. A delimitação entre o mundo adulto e o infantil é tênue e as crianças, muitas vezes, na ânsia de corresponder aos desejos, ainda que inconscientes, dos pais, procuram compensar suas frustrações, corresponder às suas expectativas, apaziguar sua angústia, negando sua própria infância.

Ao escrever Sobre o narcisismo: uma introdução, em 1914, Freud alerta para a face narcísica do amor parental: procuramos resgatar, através dos nossos filhos, a nossa infância perdida, nossos sonhos e ideais. Sua Majestade, o Bebê, nada mais é do que o bebê que outrora fomos ou que gostaríamos de ter sido. E se é fundamental este investimento dos pais em seu filho para que este cresça e se desenvolva, por outro, um amor parental que desconsidere a singularidade da criança e sua visão de mundo pode ter como resultado "pequenos adultos", precoces, mas desconfortáveis em um papel que ultrapassa sua possibilidade emocional. Não estamos desconsiderando os avanços enormes do século XXI,

* Doutora em Psicologia Clínica. Docente da Pontifícia Universidade Católica do Rio de Janeiro-PUC-Rio. Coordenadora do curso de especialização em Psicologia Clínica com Crianças da PUC-Rio. 
que possibilitam às crianças uma ampla gama de informação, acesso ao mundo e muitas formas criativas de relacionamento; no entanto, não corremos o risco de apagar a infância, ao valorizarmos somente atribuições reconhecidas no mundo adulto, como competitividade, independência e uma sexualidade precoce mas não infantil?

\section{FREUD E A SEXUALIDADE INFANTIL}

A sexualidade proposta por Freud é uma sexualidade ampliada e radicalmente diferente da concepção naturalista predominante no final do século XIX, quando a normalidade sexual era definida pela sexualidade adulta e a consumação do ato sexual referida a fins de reprodução. A masturbação infantil, a simples busca do prazer sexual, ou ainda a impossibilidade do ato sexual (como em alguns casos de impotência) eram consideradas condutas anormais (perversas) ou sinais de degenerescência.

Sobre tal pano de fundo, Freud (1905/1976a) propõe a idéia de uma sexualidade que surgiria desde os primórdios da constituição do psiquismo e seria radicalmente diferente da então aceita noção de instinto sexual.

A concepção clássica de instinto tem como modelo um comportamento que se caracteriza por sua finalidade fixa e pré-formada, com um objeto e objetivo determinados, enquanto a noção freudiana de sexualidade defende a idéia de que a sexualidade humana não é instintiva, pois o homem busca o prazer e a satisfação através de diversas modalidades, baseadas em sua história individual e ultrapassando as necessidades fisiológicas fundamentais. Assim, se a sexualidade se inicia com a anatomia (no nascimento), sua conquista depende de um longo percurso durante a construção da subjetividade da criança.

Ao indicar o pluralismo dos componentes da sexualidade infantil, Freud se afasta da moral repressora de sua época, que só aceitava uma sexualidade baseada no instinto, o qual surgiria a partir da puberdade e teria como finalidade a reprodução. $\mathrm{O}$ autor denomina a sexualidade das crianças de perverso-polimorfa, por se afastar do modelo genital de relação sexual, procurando formas de prazer derivadas de qualquer área ou órgão do corpo. O auto-erotismo infantil é destacado justamente pelo fato de que na infância a sexualidade é autoerótica, sendo o corpo da criança o único meio de obter gratificação em circunstâncias normais. Assim sendo, mesmo se as fantasias sexuais são dirigidas a um objeto (outra pessoa), a gratificação sexual é buscada em seu corpo ou em determinadas áreas do corpo que são privilegiadas em um determinado momento do desenvolvimento.

O autor toma como exemplo a amamentação do recém-nascido, sugerindo que a nutrição, a necessidade biológica de ser alimentado, não parece ser o único objetivo do bebê ao mamar. Ao contrário, observa Freud (1905/1976a) em "Três Ensaios sobre a teoria da sexualidade", "quando vemos um bebê saciado deixar o seio e cair para trás adormecido, com um sorriso de satisfação nas faces rosadas, não podemos deixar de dizer que esta imagem é o protótipo da expressão da satisfação sexual na existência posterior". Poderíamos acrescentar que o bebê procura se nutrir não só do leite materno (necessidade orgânica), mas de uma relação afetiva que não se reduz à satisfação alimentar, apesar de se apoiar nela. Freud vai utilizar o termo apoio para demonstrar que se a sexualidade se apóia em uma função de conservação da vida, vai se destacar dela ao buscar uma satisfação que excede esta função instintiva.

Como indica Garcia-Roza (1988), o objeto do instinto é o alimento, enquanto o objeto da libido é o seio materno - um objeto que é externo ao corpo. Para Freud (1905), quando este objeto é abandonado e o bebê começa a fantasiar o seio, sugando seu próprio polegar, tem início o auto-erotismo e podemos falar de uma sexualidade que se desvia do instinto.

Nas últimas décadas, as pesquisas sobre a primeira infância ressaltaram a dimensão subjetiva do bebê, ou seja, sua procura ativa por interagir com o meio desde o nascimento. Autores como Stern (1992) e Cyrulnik (1999) indicam que o bebê possui, desde o nascimento, competências e capacidades que lhe permitem uma intensa forma de comunicação nãoverbal intensa, que procura discriminar experiências a partir de um sistema de percepções e sensações vivenciadas em seu mundo relacional. Assim, se as pesquisas sobre primeira infância, por um lado, fazem cair a noção de um bebê passivo, mero objeto do discurso e do desejo parental, ressaltando sua dimensão subjetiva e sua capacidade relacional precoce, por outro demonstram como o psiquismo infantil se constitui a partir de trocas afetivas e interações que permitem ao bebê uma experiência de co-construção e mutualidade. $\mathrm{O}$ bebê, ao ser amamentado, procura também satisfazer suas necessidades emocionais ao entrar em contato com a pele da mãe, ouvir sua voz, sentir seu olhar, ser acariciado por ela. Ou seja, uma simples amamentação permite uma intensa troca afetiva, possibilitando que mãe e bebê sejam afetados um pelo outro e iniciem uma relação afetiva e sexual. Sexual no sentido amplo, 
pois a mãe (ou quem exerce esta função) ao mesmo tempo em que cuida de seu filho, erotiza seu corpo. Este corpo é erotizado justamente por não ser apenas um pedaço de carne para os pais, mas sim, um corpo simbólico, investido de afeto e de palavras que vão marcar o bebê e lhe dar um lugar fundamental na estrutura familiar. Por este motivo, os bebês e as crianças pequenas em sofrimento demonstram seu mal-estar com sintomas físicos, através de um sintoma no corpo - de um corpo que fala, antes do advento da linguagem verbal.

\section{A IMAGEM INCONSCIENTE DO CORPO E AS ETAPAS DO DESENVOLVIMENTO PSICOSSEXUAL}

Para Freud e para os psicanalistas em geral, o corpo, além de sua dimensão biológica, é um corpo simbólico. Simbólico no sentido de que a imagem que cada um tem de si é construída na relação com os adultos que ocupam a função de pais. O narcisismo primário postulado por Freud (1914/1976c) é instituído através do investimento narcísico parental que antecipa um sujeito e um lugar para o bebê antes mesmo de seu nascimento. Ou seja, Freud inverte a lógica do narcisismo enquanto amor a si mesmo, sugerindo que é necessário um investimento do outro para que haja um investimento no eu. Neste sentido, a relação especular, o olhar materno, possibilita à criança que ela se reconheça como sujeito. Olhar aqui pensado em oposição à visão, pois uma mãe reconhece em seu filho possibilidades muito maiores que sua existência presente. Por exemplo, no trabalho em unidades intensivas neonatais com bebês prematuros e suas famílias, pudemos observar como alguns pais conseguem não só olhar o bebê na incubadora, lutando contra a morte, mas ir além, atribuindo-lhe traços de identificação a familiares. "Você é teimoso como seu pai, vai lutar e sair dessa"... "Ele é nervoso como eu, vai dar trabalho"... Estes comentários, que parecem totalmente desprovidos de sentido ao serem atribuídos a bebês de 900 gramas, pouco responsivos, no entanto, mostram uma amarração simbólica entre o bebê e seus pais que conseguem atribuir àquele bebê sentimentos e características muito além de suas reais possibilidades. Se estas atribuições são pertinentes ou não, pouco importa. O importante é que aquele bebê não é olhado como uma massa de carne de baixo peso, mas reconhecido como um sujeito com um lugar insubstituível na cadeia transgeracional daquela família.

Françoise Dolto (1992), psicanalista francesa que se dedicou à clínica com crianças, oferece uma contribuição importante ao postular a noção da imagem inconsciente do corpo como a representação fantasmática do corpo que se constitui a partir da relação afetiva da criança com seus cuidadores fundamentais. A autora decompõe a palavra IMAGE, para mostra que I vem de imagem, de espelho, MA se relaciona a mamãe, pois é através desta relação especular com a mãe que o bebê constrói uma primeira representação de si mesmo, e GE se associa a $\mathrm{Eu}$ ( $e$ em francês), ressaltando a idéia de um Eu que se constitui nas trocas afetivas entre a criança e seus pais. Esta relação humaniza a criança, por ser repleta de palavras que dão sentido e significado a suas vivências, muitas vezes desorganizadas. Dolto (1992) demonstra como o esquema corporal, que é inerente à espécie, pode não corresponder à imagem inconsciente do corpo, que é construída na relação afetiva. Assim, uma criança que tenha um esquema corporal saudável pode ter uma imagem inconsciente do corpo perturbada se suas relações com as pessoas que cuidam dela se restringirem à manutenção de suas necessidades, não sendo acompanhadas de trocas afetivas que a introduzam numa relação simbólica.

A autora parte de um exemplo simples, como o da criança pequena que, ao esbarrar em uma mesa, acredita que esta é má, esperando que a mesa a console pelo "esbarrão". A criança atribui aos objetos a intencionalidade e os sentimentos que as pessoas possuem e é somente através da palavra dos pais que ela começará a estruturar-se como ser humano e a discriminar as coisas das relações humanas. Mais tarde, quando esbarrar num móvel, será com sua própria mão que ela irá se acariciar e se consolar, não mais supondo que as coisas tenham comportamentos intencionais. A introjeção da experiência da diferença entre uma coisa e uma pessoa e a vivência de ter sido cuidada por sua mãe permitem a ela transferir para si mesma a capacidade reconfortante e salvadora que apenas a mãe podia realizar para ela, podendo então se "automaternar".

Nesta perspectiva, as etapas de desenvolvimento libidinal (oral, anal e fálica) propostas por Freud (1908/1976b, 1923/1976d) têm que ser pensadas não só como privilegiadoras de zonas erógenas do corpo em um determinado momento do desenvolvimento global da criança, mas também como inscrições que se fazem no psiquismo a partir das relações estabelecidas entre a criança e os adultos que ocupam a função de pais. É preciso que uma mãe dê a seu bebê uma dimensão subjetiva, um estatuto singular para que ele possa se reconhecer, além de um corpo biológico, orgânico, como um sujeito dotado de importância para o outro. Assim, narcisismo implica na possibilidade de 
amar e reconhecer um corpo que foi investido e erotizado por um outro na infância e talvez este seja um dos motivos de, em nossa cultura, darmos tanto valor ao olhar: olhar como reconhecimento de nós mesmos, olhar como suporte de nosso eu, mas olhar também como "mau-olhado", como destruição, como perseguição.

$\mathrm{Na}$ primeira infância, o olhar e a voz são elementos privilegiados na organização do psiquismo infantil. O olhar, por ter esta dimensão de unificar o corpo do bebê, humanizando-o; a voz, por ser um referencial simbólico que dá à criança um lugar e inicia uma narrativa que mais tarde a criança vai resgatar e modificar. Assim, na fase oral, a boca se constitui não somente em um órgão privilegiado de satisfação, mas principalmente em um tipo de relação entre o bebê e a mãe. Ao mamar o bebê se nutre do leite para satisfazer uma necessidade orgânica, mas principalmente para se alimentar do olhar, da voz, do amor da mãe. Por ser um momento muito precoce da vida do bebê, a forma de relação estabelecida com a mãe é uma forma de incorporação, já que o bebê se "nutre" dela.

Autores pós-freudianos como Karl Abraham e Melanie Klein deram grande importância a esta etapa primitiva da relação, enfatizando as fantasias do bebê em relação ao seio materno - de poder devorá-lo, destruindo-o, e em contrapartida, ter medo de ser devorado pela mãe.

Ao analisarmos desenhos infantis é comum encontrarmos desenhos de tubarões com grandes dentes, bocas enormes, monstros, etc. Os contos de fadas também ressaltam esta dimensão de oralidade que aponta para sua vertente sexual e de destruição entre comer/ser comido pelo outro, como em Chapeuzinho Vermelho, Pinocchio e outros. Mesmo se não concordarmos com a interpretação kleiniana de atribuir fantasias tão sofisticadas a crianças tão pequenas, a clínica com bebês demonstra como os distúrbios de alimentação se relacionam a dificuldades nas relações precoces. A fase oral demonstra a equivalência entre alimento e amor materno, mas também a angústia entre existir e ser aniquilado, justamente por ser uma etapa na qual a criança ainda é muito dependente de seus pais ou cuidadores, sentindo os efeitos desta privação ou de distúrbios nesta relação através de seu corpo, muitas vezes de maneira grave e radical.

Inúmeras pesquisas sobre primeira infância demonstram como a privação de uma relação afetiva pode ter efeitos devastadores no desenvolvimento da criança. Renée Spitz (1945), pioneiro na observação de bebês, logo após a Segunda Guerra Mundial observou bebês separados de seus pais (órfãos ou abandonados) e deixados em abrigos ou hospitais onde eram cuidadas fisicamente, mas recebiam pouco afeto ou atenção de forma constante. $\mathrm{O}$ autor mostra os efeitos devastadores da falta de atenção qualitativa aos bebês, descrevendo a síndrome do "hospitalismo", na qual o bebê gradualmente perde o interesse pelo meio que o cerca, torna-se apático, sem tonicidade motora, podendo deixar de se alimentar, e em casos extremos de privação materna, até mesmo morrer. Este exemplo demonstra como um bebê pode abandonar seu desejo de viver, pode se fechar ao mundo, se os cuidados que lhe são prestados só tiverem como objetivo sua sobrevivência, e não se situarem na dialética do desejo e da demanda, se a nutrição não for investida de amor e atenção.

A dimensão única da sexualidade na infância se refere à sua associação direta com a relação afetiva estabelecida entre a criança e seus cuidadores. Assim, ao cuidar de seu corpo, a criança está internalizando a função maternante de seus pais. Ao sentir uma excitação física, ela vai inicialmente precisar de adultos que acolham sua excitação desorganizada e lhe dêem um contorno simbólico e afetivo. Ferenczi (1933/1980), psicanalista húngaro contemporâneo de Freud, escreveu um texto belíssimo em 1933, "Confusão de línguas entre o adulto e a criança", indicando a diferença entre o mundo adulto, marcado pela sexualidade genital e pela paixão, e o mundo infantil, marcado pela linguagem da ternura. $\mathrm{O}$ autor não pretendia desconsiderar a paixão e o desejo de uma criança, mas enfatizar que, mesmo quando seduz o adulto, a criança exerce a sedução para garantir um lugar de reconhecimento e amor perante este. Cabe ao adulto não interpretar a sexualidade infantil atribuindo-lhes significados adultos, mas sim, reconhecer sua forma de comunicação, sua demanda de amor.

\section{DA CRIANÇA AO INFANTIL}

Freud, em toda a sua obra, deu uma grande importância à sexualidade infantil justamente por reconhecer ser valor estruturante: as teorias sexuais infantis permitem à criança interpretar o enigma de sua existência, construindo, através de sua fantasia, um lugar subjetivo que the permite descolar-se da posição de alienação original no discurso parental.

A noção de uma sexualidade infantil ampliada e extragenital enfatiza também seu caráter relacional, ou seja, de como a constituição do sujeito se dá na relação com seus outros fundamentais, desconstruindo qualquer idéia de uma condição humana biológica, instintiva e natural. Ao 
contrário, a atualidade das teorias sexuais infantis propostas por Freud está na clínica com crianças, que atesta seu caráter irredutível: mesmo sendo bombardeada por um excesso de tecnologia e informação, a criança desafia a razão lógica ao construir sua própria verdade em seu próprio tempo lógico, e não cronológico.

Neste sentido, ao enfatizar o fator infantil no adulto, indicando como o adulto é moldado de ponta a ponta pelos conflitos, traumas e desejos da criança, Freud ressalta o valor do infantil que é recalcado no adulto e que uma criança coloca em cena, com sua sexualidade. $\mathrm{O}$ infantil em Freud se refere a dois planos: o plano da constituição do sujeito através da construção das teorias sexuais infantis e da realidade psíquica da criança; e o infantil ,que se mantém como um núcleo inconsciente presente na criança e no adulto, relacionado não a um tempo cronológico, mas a um tempo de retroação subjetiva.

A sexualidade infantil confronta o adulto com sua própria infância perdida, colocando-o diante de um impasse: reconhecê-la, podendo acompanhar as crianças em seu percurso subjetivo, ou negá-la, para não se deparar com suas frustrações, conflitos e desejos infantis. Manter a importância da concepção freudiana sobre a sexualidade infantil é reconhecer sua dimensão singular e estruturante: singular por estar referida à construção da subjetividade a partir da representação psíquica da relação corpo a corpo com o outro; e estruturante por testemunhar as marcas relacionais que funcionam como referentes para uma apropriação narrativa a posteriori.

\section{REFERÊNCIAS}

Cyrulnik, B. (1999). Não adianta gritar, é preciso gritar no momento certo. Em M. Soulé \& B. Cyrulnik (Orgs.), A inteligência anterior à palavra. Porto Alegre: Artes Médicas.
Dolto, F. (1992). A imagem inconsciente do corpo. São Paulo: Perspectiva.

Ferenczi, S. (1980). Confusion of tongues between adults and the child. In Final contributions to the problems and methods of psycho-analysis. New York: Brunner \& Mazel. (Original publicado em 1933).

Freud, S. (1976a). Três Ensaios sobre as teorias da sexualidade (J. Salomão, Trad.). Edição Standard Brasileira das Obras Psicológicas completas de Sigmund Freud (Vol. VII ). Rio de Janeiro: Imago. (Original publicado em 1905).

Freud, S. (1976b). Sobre as teorias sexuais das crianças (J. Salomão, Trad.). Edição Standard Brasileira das Obras Psicológicas Completas de Sigmund Freud (Vol. IX). Rio de Janeiro: Imago. (Original publicado em 1908).

Freud, S. (1976c). Sobre o narcisismo: uma introdução (J. Salomão, Trad.). Edição Standard Brasileira das Obras Psicológicas Completas de Sigmund Freud (Vol. XIV). Rio de Janeiro: Imago. (Original publicado em 1914).

Freud, S. (1976d). A organização genital infantil (J. Salomão, Trad.). Edição Standard Brasileira das Obras Psicológicas Completas de Sigmund Freud (Vol. XIX). Rio de Janeiro: Imago. (Original publicado em 1923).

Garcia-Roza, L. A. (1988). Freud e o inconsciente. Rio de Janeiro: Jorge Zahar.

Laplanche, J. (1997). Freud e a sexualidade. Rio de Janeiro: Jorge Zahar.

Spitz, R. (1945). Hospitalism: An inquiry into the gênesis of psychiatric conditions in early childhood. Psychoanalytic Study of the Child, 1, 53-72.

Stern, D. (1992). O mundo interpessoal do bebê. Porto Alegre: Artes Médicas.

Recebido em 23/11/06 Aceito em 06/03/07

Endereço para correspondência:

Silvia Maria Abu-Jamra Zornig. Rua Sara Vilela,100, Jardim Botânico, CEP 22460-180, Rio de Janeiro-RJ.E-mail: silvia.zornig@terra.com.br 